\title{
Flexible, Mechanically Robust, Solid-State Electrolyte Membrane with Conducting Oxide-enhanced 3D Nanofiber Networks for Lithium Batteries
}

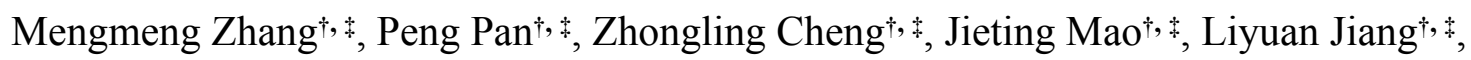

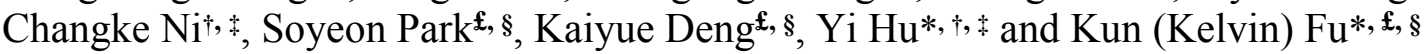

$\dagger$ Key Laboratory of Advanced Textile Materials and Manufacturing Technology, Ministry of Education, Zhejiang Sci-Tech University, Hangzhou 310018, P. R. China

*Engineering Research Center for Eco-Dying \& Finishing of Textiles, Ministry of Education, Zhejiang Sci-Tech University, Hangzhou 310018, P. R. China

${ }^{£}$ Department of Mechanical Engineering, University of Delaware, Newark, DE 19716, USA

$\S$ Center for Composite Materials, University of Delaware, Newark, DE 19716, USA

Corresponding author at:

*E-mail address: huyi-v@zstu.edu.cn (Y.Hu)

*E-mail address: kfu@udel.edu (K. (Kelvin) Fu)

Keywords: Solid-state electrolyte, mechanical robustness, 3D conducting nanofibers, flexible membrane, polymer composite 


\section{Methods}

Synthesis of LLZO powders. Nano-sized cubic-phase LLZO powders were prepared employing a simple one-step Pechini sol-gel method. ${ }^{[1]}$ First, stoichiometric amounts of nitrates, including $\mathrm{C}_{6} \mathrm{H}_{8} \mathrm{O}_{7} \bullet \mathrm{H}_{2} \mathrm{O}\left(\mathrm{M}_{\mathrm{w}}=210.14 \mathrm{~g} \mathrm{~mol}^{-1}, \mathrm{AR}, 99 \%\right), \mathrm{LiOH}\left(\mathrm{M}_{\mathrm{w}}=23.95 \mathrm{~g} \mathrm{~mol}^{-1}\right.$, 99.9\% metal basis, Aladdin), $\mathrm{La}\left(\mathrm{NO}_{3}\right)_{3} \cdot 6 \mathrm{H}_{2} \mathrm{O}\left(\mathrm{M}_{\mathrm{w}}=433.01 \mathrm{~g} \mathrm{~mol}^{-1}, \mathrm{AR}, 99 \%\right.$, MACKLIN $)$, $\mathrm{ZrO}\left(\mathrm{NO}_{3}\right)_{2} \bullet \mathrm{xH}_{2} \mathrm{O}\left(\mathrm{M}_{\mathrm{w}}=231.23 \mathrm{~g} \mathrm{~mol}^{-1}, 99.99 \%, \mathrm{MACKLIN}\right), \mathrm{Al}\left(\mathrm{NO}_{3}\right)_{3} \bullet 9 \mathrm{H}_{2} \mathrm{O}\left(\mathrm{M}_{\mathrm{w}}=375.13\right.$ g mol${ }^{-1}, 99.99 \%$, MACKLIN $)$ and $\mathrm{NbCl}_{5}\left(\mathrm{M}_{\mathrm{w}}=270.17 \mathrm{~g} \mathrm{~mol}^{-1}, 99.9 \%\right.$ metal basis, MACKLIN) were dissolved in deionized water and stirred and heated to obtain homogeneous solution. Second, a brown porous gel was obtained after drying the sol at $250{ }^{\circ} \mathrm{C}$ for $3 \mathrm{~h}$. At the end of the process, the dried gel was calcined at $850{ }^{\circ} \mathrm{C}$ for $2 \mathrm{~h}$ in air atmosphere in a muffle furnace to obtain LLZO nanoparticles.

Fabrication of $\mathbf{L L Z O} / \mathbf{h}$-polymer nanofiber. Polyvinylidene fluoride (PVDF, $\mathrm{M}_{\mathrm{w}}=400,000$ $\mathrm{g} \mathrm{mol}{ }^{-1}$, MACKLIN) was dried at $80{ }^{\circ} \mathrm{C}$ for $24 \mathrm{~h}$ under vacuum. PVDF, LLZO, Lithium bis(trifluoromethanesulfonimide) (LiTFSI, $\mathrm{M}_{\mathrm{w}}=287.09 \mathrm{~g} \mathrm{~mol}^{-1}, 99 \%$, Aladdin) and polyethylene oxide $\left(\mathrm{PEO}, \mathrm{M}_{\mathrm{w}}=600,000 \mathrm{~g} \mathrm{~mol}^{-1}\right)$ were dissolved in a polymer concentration of 8 wt.\% of N, N-dimethylformamide (DMF). The weight of LiTFSI was $0.1 \mathrm{~g}$. The weight percentages of LLZO were 0, 10, 20, and $30 \mathrm{wt} . \%$ of LLZO and PVDF, respectively (xLLZO/h-polymer nanofiber, $x=10,20,30$. Unless otherwise noted, the LLZO/h-polymer in the text and the Figures are 20-LLZO/polymer, respectively.) and the weight percentage of PEO was 5 wt.\% of PVDF, followed by mechanical stirring at $40{ }^{\circ} \mathrm{C}$ overnight to obtain a homogeneous solution.

The electrospinning process was carried out with a feed rate of $0.8 \mathrm{~mL} \mathrm{~h}^{-1}$, a voltage of $15 \mathrm{kV}$ and a distance of $13 \mathrm{~cm}$ between the needle and drum collector. The rotation speed was maintained at $350 \mathrm{rpm}$. The humidity and temperature of the electrospinning chamber were approximately $30 \%$ and $35{ }^{\circ} \mathrm{C}$, respectively. After electrospinning, the as-spun LLZO/hpolymer nanofiber membrane were kept in a vacuum oven at $60{ }^{\circ} \mathrm{C}$ overnight.

Preparation of LLZO/h-polymer composite electrolyte. A homogeneous solution was prepared by dissolving PEO and LiTFSI in acetonitrile $\left(\mathrm{M}_{\mathrm{w}}=41.05, \mathrm{AR}, 99 \%\right.$, MACKLIN). The molar ratio of EO: $\mathrm{Li}$ was set to 20: 1 . After stirring for $24 \mathrm{~h}$, the homogeneous mixture was coated onto the LLZO/polymer nanofiber membrane and dried at $50{ }^{\circ} \mathrm{C}$ for $24 \mathrm{~h}$ in vacuum to obtain LLZO/h-polymer composite electrolyte for conductivity and battery tests.

Materials characterization. The morphologies and structures of the LLZO/polymer nanofiber membranes and LLZO/polymer composite electrolyte were examined using field emission scanning electron microscopy (SEM; Zeiss Ultra 55) with energy dispersive X-ray 
spectroscopy (EDX). Powder X-ray diffraction (XRD; Thermo ARL XTRA) was used to identify the crystal phases of ceramic particles. Fourier transform infrared (FTIR, Nicolet 57000) spectroscopy was employed to analyze the structural transformation of the solid electrolyte membranes with and without LLZO. Thermogravimetric analysis (TGA; Shimadzu60) was performed under $\mathrm{N}_{2}$ atmosphere at a heating rate of $20{ }^{\circ} \mathrm{C} \mathrm{min}-1$ to determine the content of LLZO in the composite electrolyte. The tensile mechanical properties of the solid electrolyte membranes were investigated using a multifunctional drawer (Intro-5943).

Electrochemical characterization. For ionic conductivity measurements, LLZO/h-polymer composite electrolyte was assembled into a coin cell with stainless steel (SS) blocking electrodes. Electrochemical impedance spectroscopy (EIS) was performed in the temperature range of $30-80{ }^{\circ} \mathrm{C}$ using a Zahner Zennium electrochemical workstation in the frequency range of $1 \mathrm{MHz}$ to $0.1 \mathrm{~Hz}$. The ionic conductivity $(\sigma)$ is given by Equation (1):

$$
\sigma=\mathrm{L} / \mathrm{RS}, \quad(1)
$$

where $\mathrm{R}$ is the resistance value of the bulk solid electrolyte; $\mathrm{L}$ is the thickness of the electrolyte membrane $(\sim 150 \mu \mathrm{m})$, and $\mathrm{S}$ is the effective area of contact between the electrolyte and the stainless-steel blocking electrode $\left(\sim 1.13 \mathrm{~cm}^{2}\right)$.

For the lithium ion transference number measurements, Li | LLZO/h-polymer | Li symmetric cells were assembled to test the potentiostatic direct current (DC) polarization and EIS measurements. The lithium ion transference number $\left(t_{L i}+\right)$ was calculated using Equation (2):

$$
t_{L i}{ }^{+}=\frac{I_{s}\left(\Delta \mathrm{V}-I_{0} R_{1}^{0}\right)}{I_{0}\left(\Delta \mathrm{V}-I_{s} R_{1}^{s}\right)},
$$

where $\Delta \mathrm{V}$ is the applied DC voltage $(10 \mathrm{mV}) ; I_{0}$ and $I_{S}$ are the initial and steady currents, respectively, and $R_{1}^{0}$ and $R_{1}^{S}$ are the charge-transfer resistances before and after DC polarization, respectively.

$\mathrm{Li} \mid \mathrm{LLZO} / \mathrm{h}$-polymer | SS batteries were used to test the electrochemical stability window through a linear sweep voltammetry (LSV) test at $50{ }^{\circ} \mathrm{C}$ at a rate of $1 \mathrm{mV} \mathrm{s}^{-1}$ in the voltage range of $2-6 \mathrm{~V}$. The lithium stripping/plating test was performed at $50{ }^{\circ} \mathrm{C}$ with a current density of $0.1 \mathrm{~mA} \mathrm{~cm}^{-2}$ for $0.5 \mathrm{~h}$ charge and $0.5 \mathrm{~h}$ discharge.

All-solid-state batteries (CR2032 coin-type) were assembled by the $\mathrm{LiFePO}_{4}$ cathode material, composite electrolyte, and lithium anode in a glove box with argon atmosphere. The $\mathrm{LiFePO}_{4}$ (LFP) cathode was prepared by dispersing LFP/Super P/PEO/LiTFSI in acetonitrile at a weight ratio of $6: 1: 2: 1$ to form a uniform slurry, which was coated on an aluminum foil current collector and dried at $60{ }^{\circ} \mathrm{C}$ for $24 \mathrm{~h}$ under vacuum. The active material loading of the LFP cathode was approximately $1.5 \mathrm{mg} \mathrm{cm}^{-2}$. The cycling performance of the all-solid-state 
battery was tested at $50{ }^{\circ} \mathrm{C}$ with a current density of $0.2 \mathrm{C}\left(1 \mathrm{C}=170 \mathrm{~mA} \mathrm{~g}{ }^{-1}\right)$ in the voltage range of 2.5-4.0 V. All-solid-state flexible pouch lithium metal batteries were assembled using LFP and a lithium metal tape as the cathode and anode, respectively, and LLZO/h-polymer composite electrolyte as the solid electrolyte and separator, with aluminum-plastic as the packaging material. 

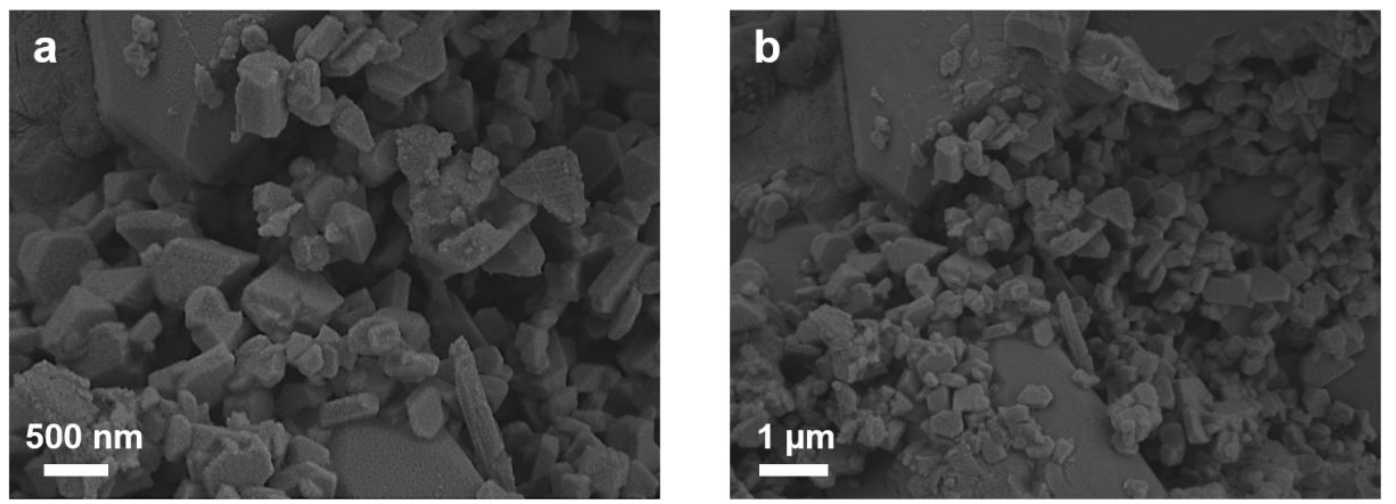

Supplementary Fig. 1. SEM image of LLZO particles at a, high and b, low magnification. 

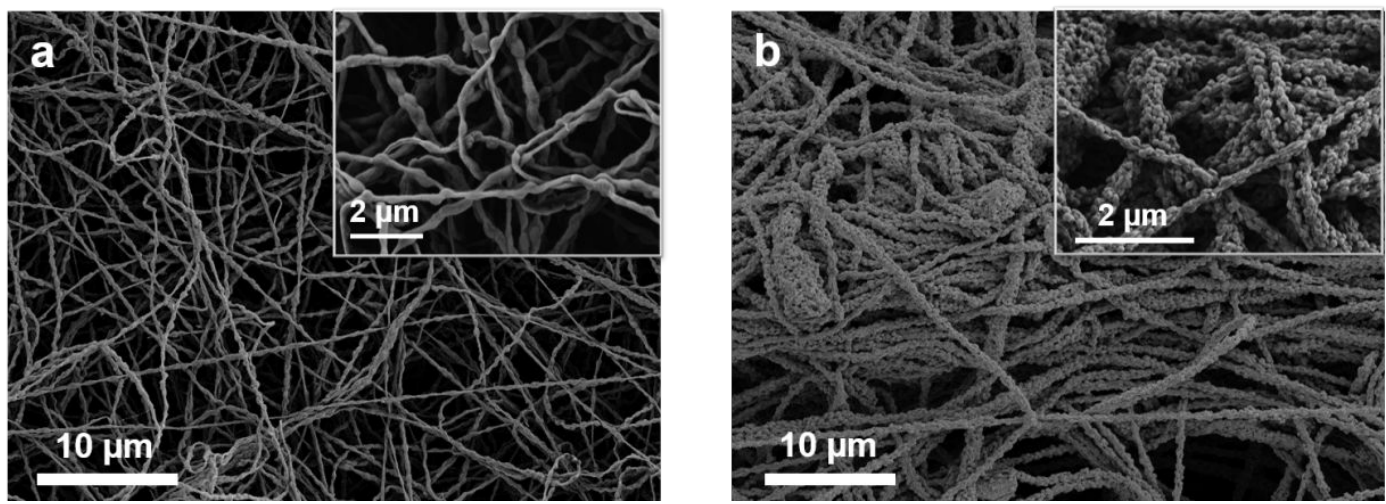

Supplementary Fig. 2. SEM images of a, 10-LLZO/h-polymer nanofiber and b, 30LLZO/h-polymer nanofibers. 


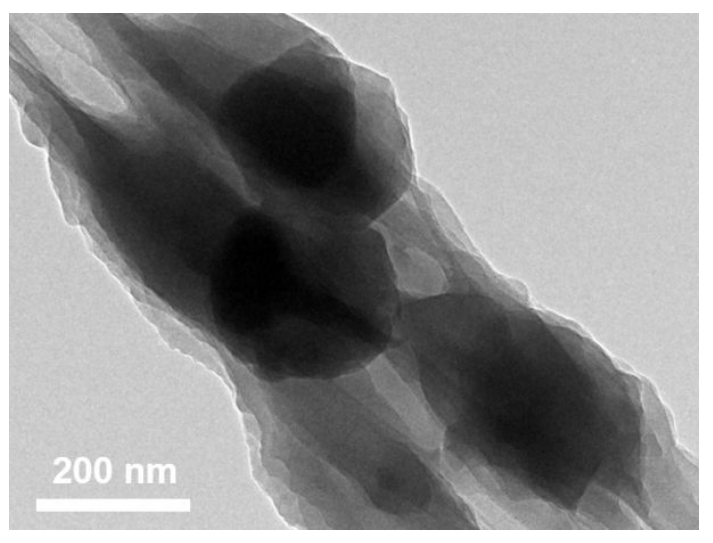

Supplementary Fig. 3. TEM images of 20-LLZO/h-polymer nanofiber in high magnification. 

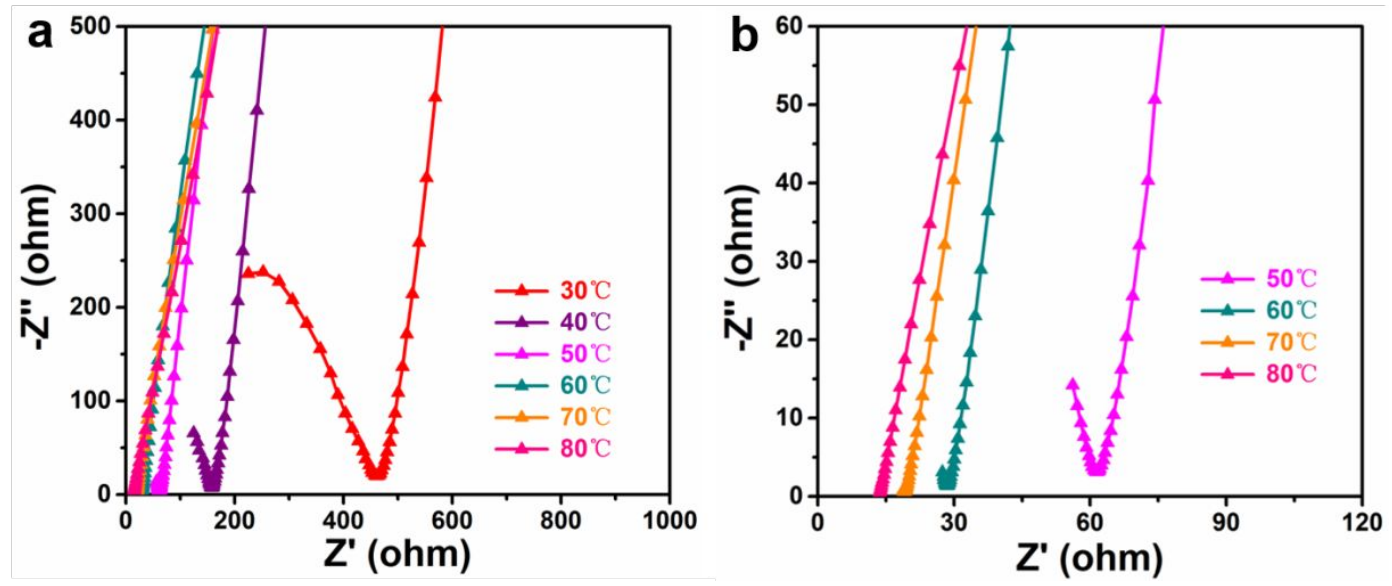

Supplementary Fig. 4. EIS plot of composite electrolyte with LLZO/h-polymer (PVDFPEO with LiTFSI) nanofiber at different temperatures: $\mathrm{a}, 30-80^{\circ} \mathrm{C}$ and $\mathrm{b}, 50-80^{\circ} \mathrm{C}$. 

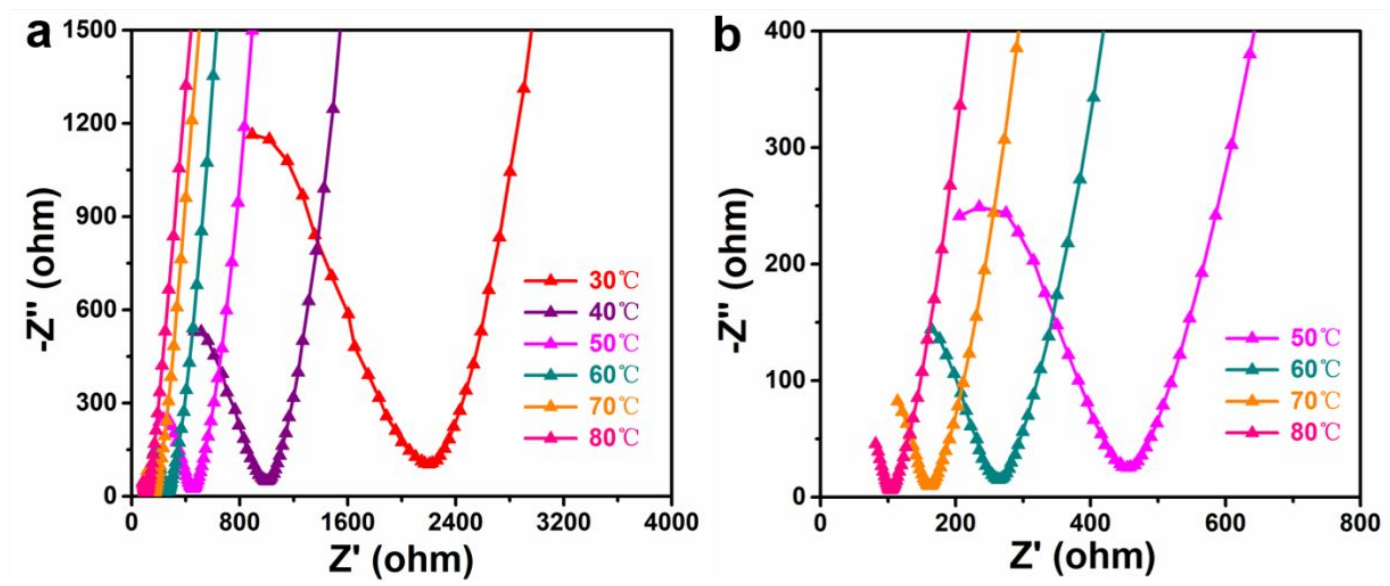

Supplementary Fig. 5. EIS plot of composite electrolyte with h-polymer nanofibers at different temperatures: $\mathrm{a}, 30-80^{\circ} \mathrm{C}$ and $\mathrm{b}, 50-80{ }^{\circ} \mathrm{C}$. 


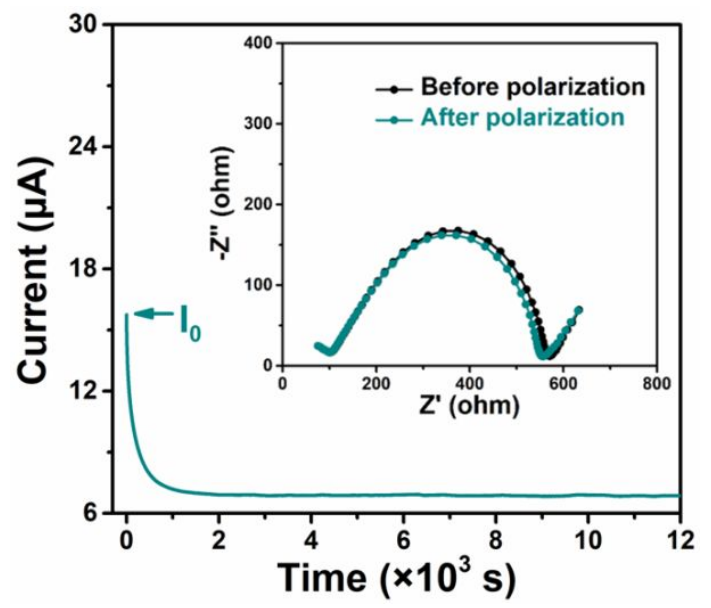

Supplementary Fig. 6. Chronoamperometry profile of Li | h-polymer | Li symmetric batteries; inset: the Nyquist impedance spectra of batteries before and after polarization. 


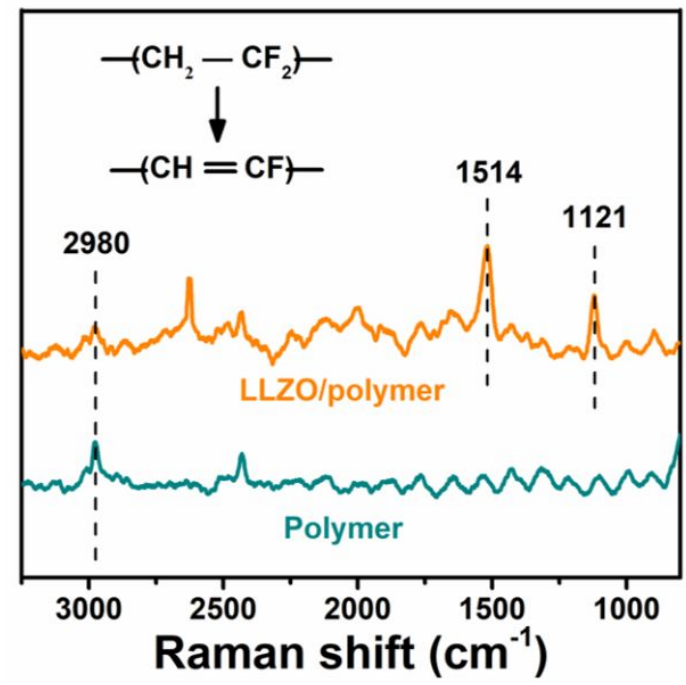

Supplementary Fig. 7. Raman spectrum of composite electrolyte with h-polymer nanofibers and composite electrolyte with LLZO/h-polymer nanofibers. 


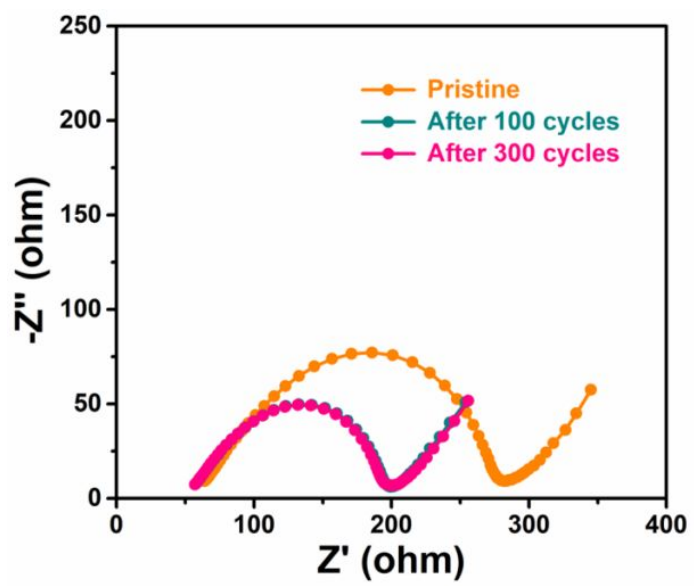

Supplementary Fig. 8. Electrochemical impedance plots of $\mathrm{Li} / \mathrm{Li}$ cells before and after cycle of composite electrolyte with LLZO/h-polymer nanofibers. 


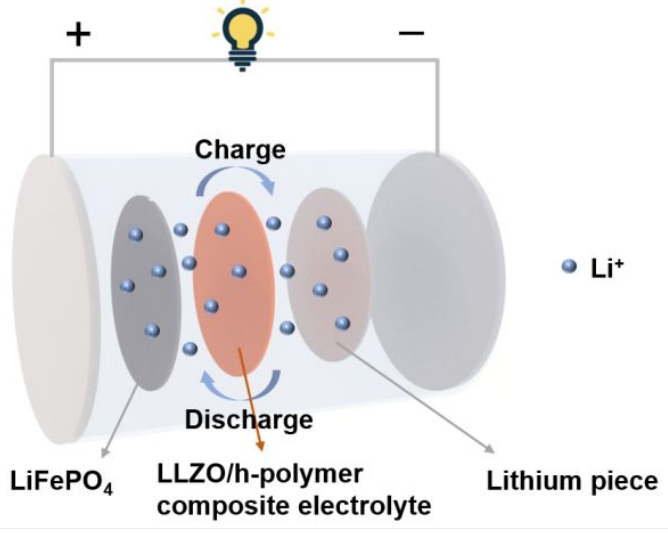

Supplementary Fig. 9. The schematic of $\mathrm{LiFePO}_{4} \mid \mathrm{LLZO} / \mathrm{h}-$ polymer $\mid \mathrm{Li}$ full cell. 


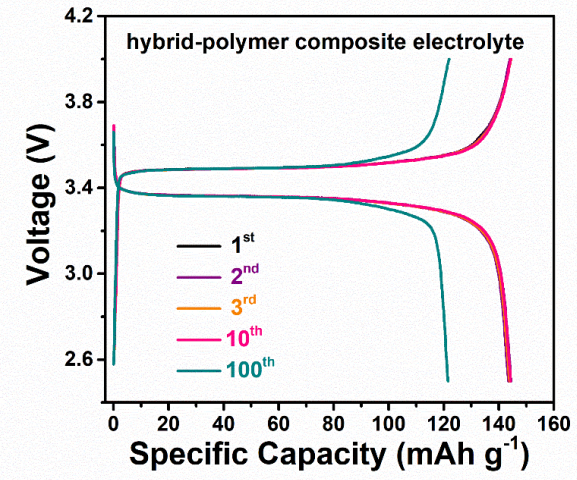

Supplementary Fig. 10. Charge and discharge curves of $\mathrm{LiFePO}_{4} \mid$ h-polymer $\mid \mathrm{Li}$ battery at different number of cycles under $0.2 \mathrm{C}$ at $50^{\circ} \mathrm{C}$. 


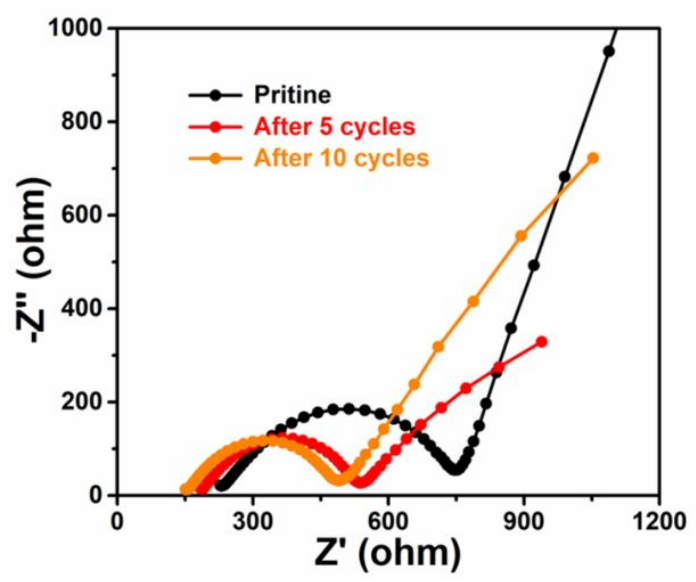

Supplementary Fig. 11. Electrochemical impedance plots of $\mathrm{LiFePO}_{4} / \mathrm{Li}$ cell of composite electrolyte with $\mathrm{LLZO} / \mathrm{h}$-polymer nanofibers before and after cycle at $50{ }^{\circ} \mathrm{C}$.

\section{Supplementary Movie 1}

The LLZO/h-polymer nanofiber membrane after being squeezed into a cluster by external force with a few wrinkles in unfolding and paving without broken. 


\section{References}

1. Tao, X.; Liu, Y.; Liu, W.; Zhou, G.; Zhao, J.; Lin, D.; Zu, C.; Sheng, O.; Zhang, W.; Lee, H.-W.; Cui, Y. Solid-State Lithium-Sulfur Batteries Operated at $37{ }^{\circ} \mathrm{C}$ with Composites of Nanostructured $\mathrm{Li}_{7} \mathrm{La}_{3} \mathrm{Zr}_{2} \mathrm{O}_{12}$ /Carbon Foam and Polymer. Nano Lett. 2017, 17, (5), 2967-2972. 